\title{
Dry particle high coating of biopowders: An energy approach
}

\author{
S. Otles, O. Lecoq *, J.A. Dodds \\ RAPSODEE Research Center Ecole des Mines d'Albi-Carmaux, 81013 Albi, France
}

Keywords:
Dry coating
Coating strength
Energy
Adhesion
Hybridizer
Cyclomix

Cyclomix

\begin{abstract}
A B S T R A C T
The general aim of this paper is to study the coating strength of different composite powders with an experimental approach based on mixing energy descriptors derived from linear velocity at the end of paddles. The chosen system is Cellets particles coated with Talc particles, with two size ratios: 7 and 22. The studied processes are Nara Hybridizer NHS-0, 1 litre Hosokawa Cyclomix, Turbula mixer and finally "Basic Mixing". The developed energy analysis leads to quantitative comparison of the equipment and helps to show the specific dry coating improvement in term of coating strength compared to the simple ordered mixing phenomenon.

According to the chosen energy descriptors, in accordance with the litterature, the Hybridizer is the higher energy system and leads with the chosen operating conditions to the stronger coating. If we compare the other processes, the increase of mixing energy always leads to an increase of coating strength as soon as breakage is avoided. This can be possible by choosing the adapted operating parameters in each system.
\end{abstract}

\section{Introduction}

Dry coating technology has become over the years an environment friendly and economical alternative compared to other classical methods. No solvents are used and it doesn't require any drying step. Some successful examples of controlled end-use properties can be found in the literature, showing successful ways of producing engineered particles [1,2].

In dry particle coating processes, small guest particles are mixed with larger (10 to 100 times) host particles in order to create valueadded composite particulate materials. According to the chosen process, the operating conditions and the material properties, different situations can be observed : from simple rebound to attrition or breakage (Fig. 1). In between, it is possible that the guest particles come into contact with the host particles through the application of mechanical forces, and create composite particles [3,4].

The coating mechanisms are complex and involve ordered mixing [5], kinetics of fine particle transfer [6], filming, embedding, attaching, electrifying, fixing, rounding etc., but it is still difficult to estimate the phenomena correctly. One challenge today is to correlate the physicochemico-mechanical phenomena to the process and the material properties (Fig. 2).

In order to improve the fundamental knowledge of dry coating, a better description of the coating equipment is necessary. In this work we developed global energy descriptors based on linear velocity at the end of the mixing paddles. This approach is largely inspired from the

\footnotetext{
* Corresponding author.

E-mail address: lecoq@enstimac.fr (O. Lecoq).
}

liquid mixing area. Within this context, we studied the influence of the process and the size ratio on the dry coating results.

\section{Experimental}

\subsection{Materials}

Cellets particles were coated with Talc particles (Table 1 and Fig. 3). These Cellets are made of microcrystalline cellulose, and are mainly used for controlled release formulations and for drug delivery. In this study the Cellets were used because the particles have a regular spherical shape, smooth surface and very high mechanical strength. Talc is used in food and pharmaceutical industry as an effective anticaking agent and lubricant. The size ratio of the powder couples are $100 / 14=7$ and $305 / 14=22$.

\subsection{Methods}

\subsubsection{Equipments tested}

In this study a Hybridizer (NHS - 0, Nara Machinery, Japan), a Cyclomix (capacity one litre, Hosokawa Micron B.V., Japan) and a Turbula (WAB A.G., Switzerland) shown in Fig. 4, were used as the dry particle coating equipments. Description of these systems can be found elsewhere [7,8]. The Hybridizer and the Cyclomix are equipped with a cooling/heating jacket because they are high energy mixing systems compared to the Turbula.

The Turbula is a powder blender which allows mixing of powders inserted into a container set in a three-dimensional movement that exposes the product to an always changing, rhythmically pulsing motion. 


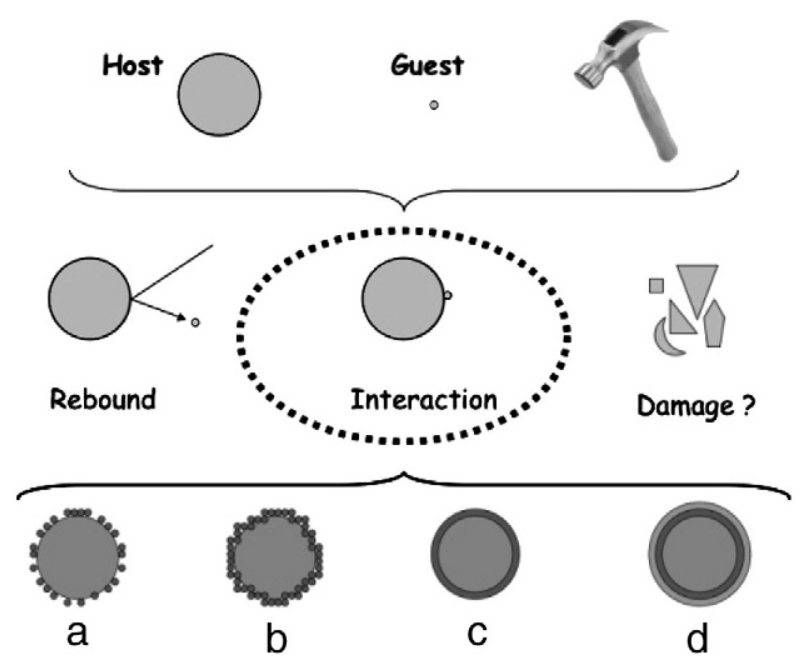

Fig. 1. Mechanical action on a powder mix of host particles and guest particles: if interaction is possible, it may lead to monolayer discrete (a), continuous porous (b), continuous film (c) or multilayer coating (d). [Adapted from [1]].

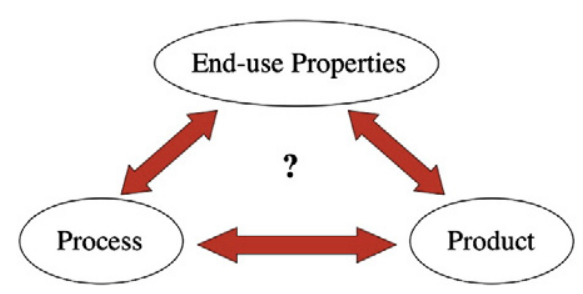

Fig. 2. Relationship chart between the three "P" for a dry coating process.

"Basic mixing", i.e. mixing manually with a spatula is carried out for comparison.

\subsubsection{Experiments conditions}

To be able to understand the effect of host particle size on the coating strength we need to avoid particle breakage or at least to minimize it. A preliminary study determined the conditions for the beginning of breakage in all the equipments. In accordance with these results, arbitrary rotational speeds were chosen below the breakage limit, as indicated in Table 2. Discussion will follow in the paper showing the difficulty to compare different apparatus with different sizes and geometries and highlighting the question : how to choose comparable operating conditions? (if possible).

The batch processing time was kept constant at 6 minutes. For the experiments with the Turbula, the Cellets host particles, were first pre-manipulated by Hybridizer at $4000 \mathrm{rpm}$ and then they were mixed with Talc in the Turbula. So we compare initial particles with similar stress history.

In this study the host particles Cellets 90 were coated with 10\% Talc, and Cellets 200 were coated with 5\% Talc. This corresponds for the two couples to $20 \%$ of the maximum coverage of the host particles by the guest particles [9].

In addition, Cellets 90 and Cellets 200 particles were also mixed with Talc particles by a simple manual mixing method called "basic mixing". Samples were prepared by simply mixing the Cellets and Talc together with a spatula for 6 minutes.

Table 1

Studied powders properties.

\begin{tabular}{llll}
\hline Materials & $\mathrm{d}[4.3](\mu \mathrm{m})$ & Density $\left(\mathrm{kg} / \mathrm{m}^{3}\right)$ & Origin \\
\hline Cellets 90 or 200 & 100 or 305 & 1520 & $\begin{array}{l}\text { Pharmatrans Sanaq AG, } \\
\text { Switzerland }\end{array}$ \\
Talc & 14 & 2800 & Luzenac SA, France \\
\hline
\end{tabular}

a

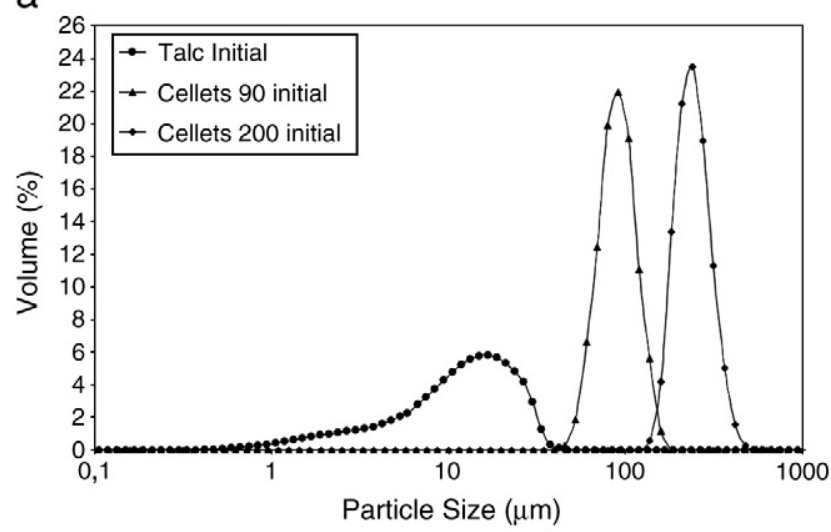

b

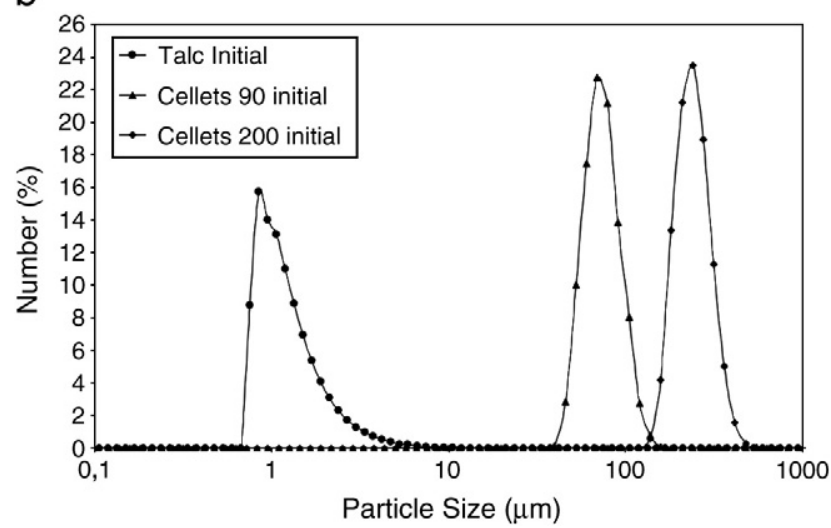

Fig. 3. Particle size distributions in volume (a) and in number (b) of the studied materials (Malvern Mastersizer).

\subsubsection{Analyses}

In this paper we determine at which dispersing air pressure (range 0.1 - 4.0 bar) the guest particles start to be detached from the host particles according to a previously developed methodology using a Malvern Mastersizer equipped with the Sirocco dry powder feeding system [10]. This "liberation" pressure, even though arbitrary, is an interesting tool to compare different coatings. We use it as an estimation of the coating strength.

\subsubsection{Mixing energy description}

If comparison of the different used processes is wanted, it can be interesting to derive global energy descriptors. However it is important to insist that the authors are well aware that these processes are working with different impeller geometries and sizes, hence different level of impact, shearing, friction... The objective here is only to set a global approach and to propose energy descriptors inspired by the liquid mixing area. The basic principle is to characterize a complex mixing system by a characteristic velocity

Table 2

Operating conditions.

\begin{tabular}{lccccc}
\hline Equipment & $\mathrm{N}(\mathrm{rpm})$ & $\mathrm{V}^{(3)}(\mathrm{m} / \mathrm{s})$ & $\mathrm{E}^{(3)}(\mathrm{J} / \mathrm{kg})$ & Mass $(\mathrm{g})$ & $\begin{array}{l}\text { Solid volume } \\
\text { fraction (\%) }\end{array}$ \\
\hline Hybridizer & 4000 & 25 & 316 & $30^{(1)}$ & 4 \\
Cyclomix & 1600 & 8 & 36 & $620^{(2)}$ & 40 \\
Turbula & 96 & 1.5 & 1.1 & 30 & 2 \\
Basic mixing & - & $\sim 1$ & 0.5 & 30 & 2 \\
\hline
\end{tabular}

(1) corresponding to the optimum filling conditions, i.e. good mixing and recirculation. (2) $500 \mathrm{ml}$ is considered classically as the minimum volume for good mixing and recirculation.

(3) explained in Table 3. 
Table 3

Equipment descriptions.

\begin{tabular}{|c|c|c|c|c|c|}
\hline Equipment & Characteristic dimension $(\mathrm{cm})$ & Rotation frequency $\mathrm{N}$ (rpm) & Characteristic velocity $\mathrm{V}(\mathrm{m} / \mathrm{s})$ & Characteristic energy E (J/kg) & Comment \\
\hline Hybridizer & $\mathrm{R}=6$ & 4000 & $2 \pi N R=25$ & $\mathrm{~V}^{2} / 2=316$ & 6 identical paddles \\
\hline Cyclomix & $\begin{array}{l}\mathrm{R}_{1}=3.5 \\
\mathrm{R}_{2}=5.0 \\
\mathrm{R}_{3}=6.3\end{array}$ & 1600 & $2 \pi N\left(\Sigma R_{i} / 3\right)=8$ & $\left(\Sigma V_{i}^{2} / 3\right) / 2=36$ & 3 pairs of different paddles \\
\hline Turbula & $\mathrm{R}=15$ & 96 & 1.5 & 1.1 & No paddle \\
\hline Basic mixing & - & - & $\sim 1$ & 0.5 & Glass stirrer \\
\hline
\end{tabular}

derived from the tip velocity of the impeller. From this velocity, kinetic energy can be calculated. The Table 3 summarizes the analysis according to the dimensions found in Fig. 4.

According to impeller classification, the Hybridizer is similar to a radial flow impeller with radial discharge of the mix from center to the walls. Whereas the Cyclomix is similar to a axial impeller, with recirculating flow downwards in the center and upwards at the walls. From classical dimensionless analysis [11], considering equivalent power numbers in turbulent regime, we define the following relation of the power of the mixer :

$P \approx \rho \cdot N^{3} \cdot D^{5}$

With $N$ the rotation frequency (revolution per second), $\rho$ the density of the mixed medium $(\mathrm{kg} / \mathrm{m} 3)$ and $D$ a characterisitic dimension of the system, here the diameter of the impeller.

\section{Results}

\subsection{Qualitative observation}

Fig. 5 shows the obtained coated particles in our tests. The S.E.M. images show that the Cellets particles are not broken in all the used mixers. Hence, it is possible to study the coating phenomenon alone, and compare the influence of the process and the size ratio on the coating quality.

\subsection{Effect of dry coating equipment on the coating strength}

The methodology used to evaluate the coating strength is based on particle size analysis by the Malvern Mastersizer in dry feed mode. Ideally, increasing the dispersing air pressure causes separation of the guest particles from the surface of the host particles at a certain level of dispersion energy. This threshold "liberation" pressure is detected by following the number fraction particle size distribution in parallel with the volume fraction particle size distribution $[9,10]$. In this paper, only the evolutions of the median number diameter $\mathrm{d}(\mathrm{N}, 50 \%)$ with increasing pressure are presented. When an detachment event occurs, the coating strength is obtained and is linked to a sudden change in this diameter, very sensitive to finer particles.

Fig. 6 shows the evolution of the number median diameters for all the initial powders alone. For the Cellets, the diameters are not changing due to the dispersion energy in the range $0.5-4$ bars in the Venturi system of the Malvern granulometer. It is supposed that the energy level reached in the dispersion system will never lead to the fragmentation of the tested particles. The decrease in diameter observed for Talc corresponds actually to a decrease of the size of the Talc agglomerates (checked with S.E.M. observation).

Figs. 7 and 8 show the variation of the diameters for the two Cellets composite particles when introduced in the dispersion test. Experimentally, when a sudden change is observed, the variation of the pression is reduced from 0.5 to 0.1 bar step increase, which corresponds to the accuracy level of the method.

In summary, the dispersing pressures for particle detachment for the two Cellets composites for each dry particle equipment are given in Table 4. According to the results, it is observed that the higher the size ratio, the larger the liberation pressure, i.e. the coating strength. This is in accordance with the literature and with the van der Waals interaction theory. The order of coating quality (strength) is, with the arbitrary chosen operating conditions : Hybridizer $>$ Cyclomix $>$ Turbula $>$ Basic Mixing. The next part will give some details of this classification in relation with energy considerations.

\section{Energy considerations}

Fig. 9 shows a new data presentation, including mixing energy decriptors defined above, i.e. the kinetic energy derived from characteristic tip impeller velocity. In our experiments, the Hybridizer
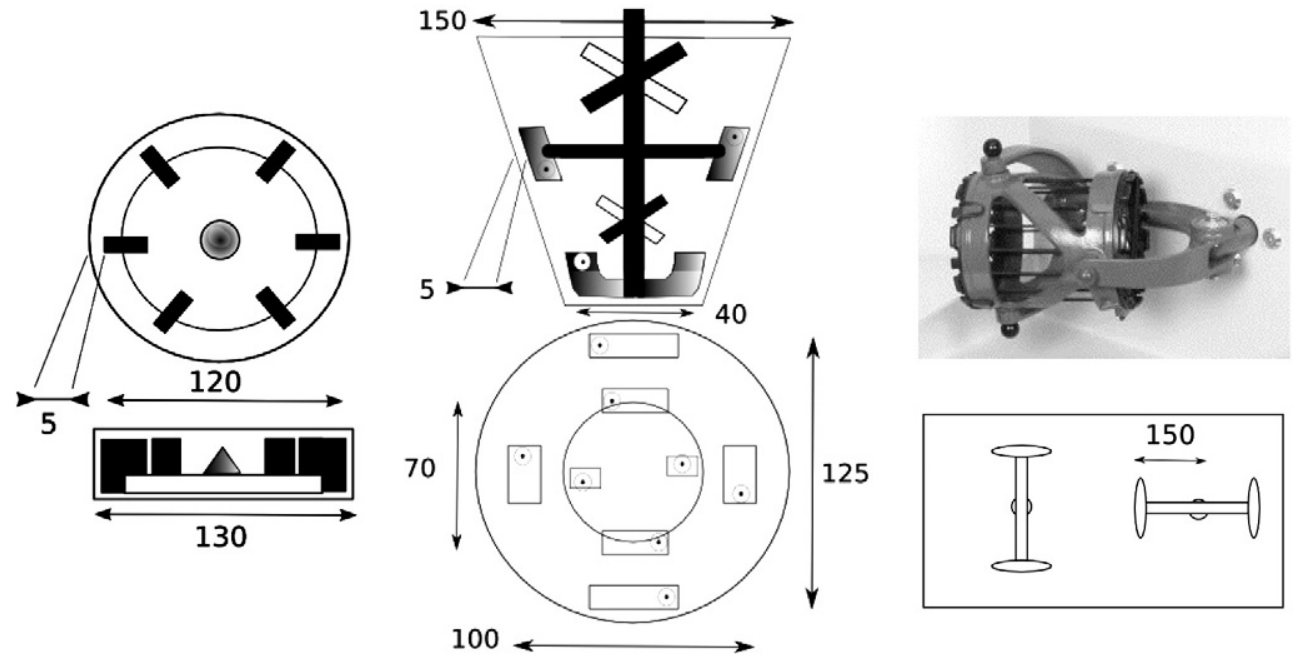

Fig. 4. Hybridizer (left), Cyclomix (center) and Turbula blender (right). 
Cellets $90+10 \%$ Talc.

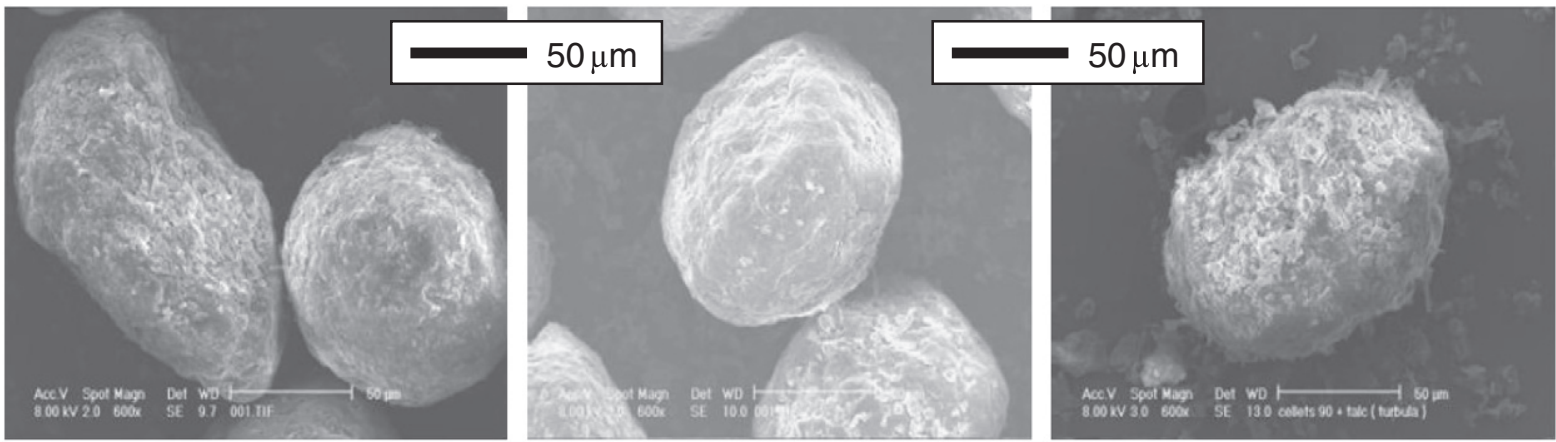

Cellets $200+5 \%$ Talc

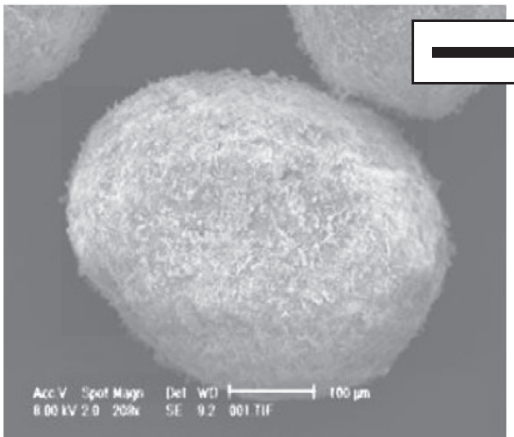

(a) Hybridizer

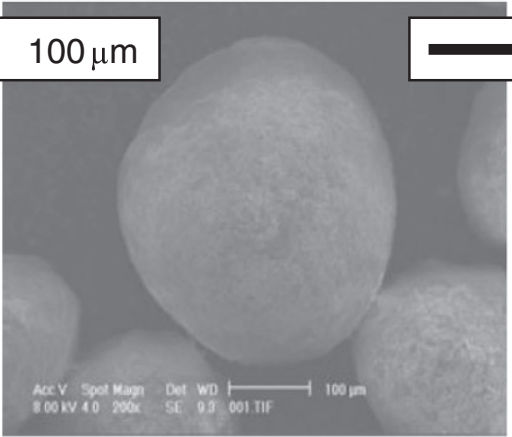

(b) Cyclomix

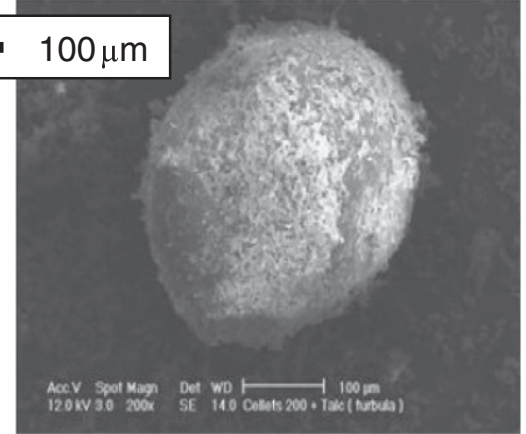

(c) Turbula

Fig. 5. S.E.M. images of the coated Cellets with Talc.

consumes the most energy and Basic Mixing uses the least. The graph shows a direct relationship between the energy provided by the equipment and the coating strength, estimated by the detachment pressure. As expected, the larger the energy given to the mix host and guests particles, the larger the detachment pressure and the better the adhesion. If we compare with ordered mixing adhesion (Basic Mixing), the coating strength obtained with high energy mixers is 3 to 4 times larger, but the energy requirement is 100 to 1000 times larger.

If we come back to relation (1), the calculations give that the mixing power of the Hybridizer is around ten times the mixing power of the Cyclomix. It is interesting to notice that the power approach (power ratio $442 / 49=9.0$ ) leads to the same order of magnitude obtained from the energy approach summarized in Table 3 (energy ratio $316 / 36=8.8$ ).

If we want to compare the two mixers at the same mixing power (power ratio $=1$ ), keeping constant the other operating conditions,

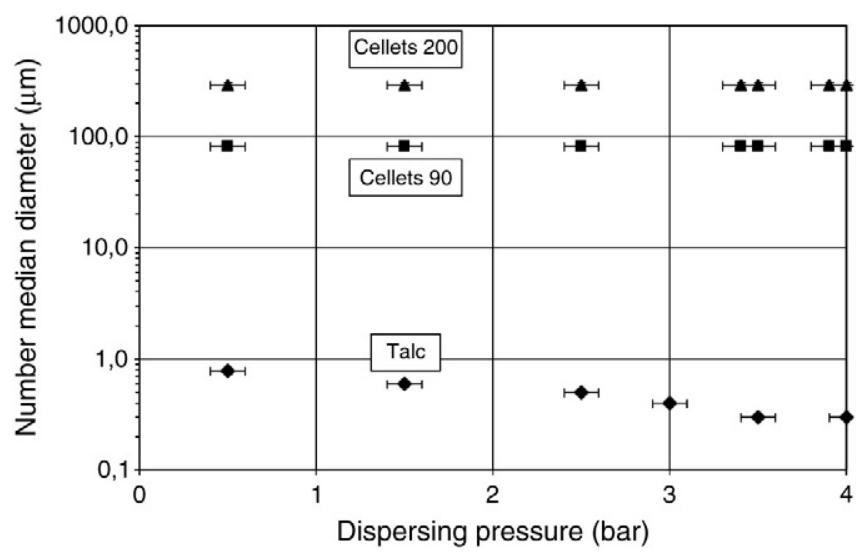

Fig. 6. Evolution of diameter with dispersing pressures for initial powders.

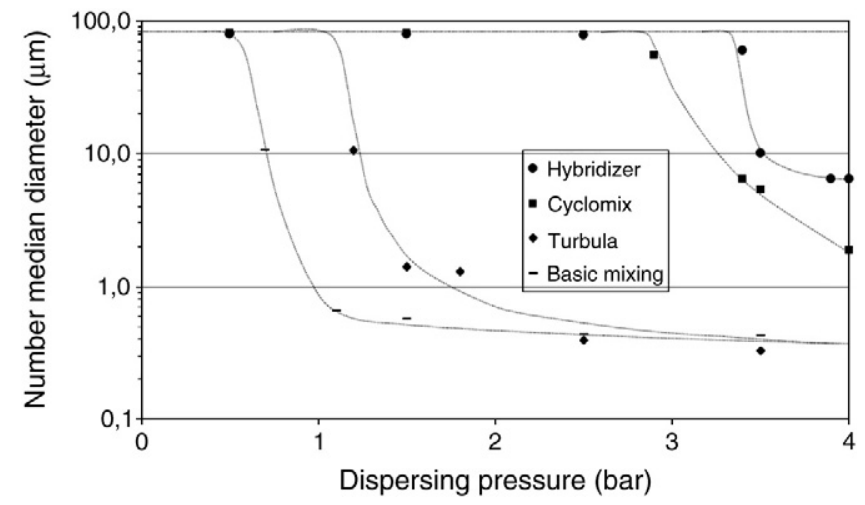

Fig. 7. Evolution of diameter with dispersing pressures for Cellets $90+10 \%$ Talc.

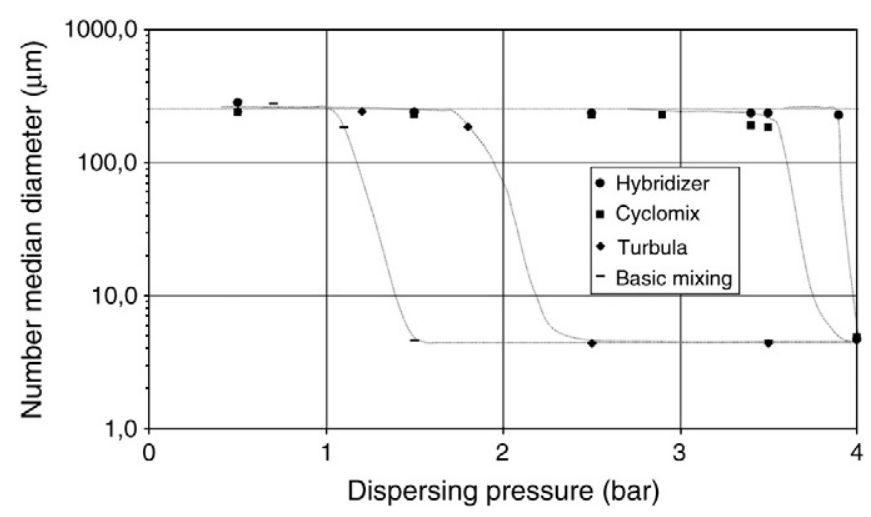

Fig. 8. Evolution of diameter with dispersing pressures for Cellets $200+5 \%$ Talc. 
Table 4

Detachment Pressures for the composites Cellets in the different equipments.

\begin{tabular}{lll}
\hline Equipments & $\begin{array}{l}\text { Detachment pressure } \\
\text { for Cellets 90 with } \\
10 \% \text { Talc [bar] }\end{array}$ & $\begin{array}{l}\text { Detachment pressure } \\
\text { for Cellets 200 with } \\
5 \% \text { Talc [bar] }\end{array}$ \\
\hline Hybridizer at $4000 \mathrm{rpm}$ & 3.4 & 3.9 \\
Cyclomix at $1600 \mathrm{rpm}$ & 2.9 & 3.4 \\
Turbula at $96 \mathrm{rpm}$ & 1.2 & 1.8 \\
Basic Mixing & 0.7 & 1.1 \\
\hline
\end{tabular}

the calculations show that the rotation speeds of the Hybridizer must be 1.6 larger than the rotation speed of the Cyclomix. If the rotation of Cyclomix is $1600 \mathrm{rpm}$, the Hybridizer should rotate at $2560 \mathrm{rpm}$ to have the same mixing power. But, it must be clear that this approach is not taking into account the geometries of the mixers and the involved mixing-coating mechanisms. This means that power-similar coating equipments shouldn't lead to the same end-use properties.

\section{Conclusion}

Dry coating is an interesting way of obtaining tailored end-use properties particles. But so far, it still lacks fundamental knowledge. This work aimed at developing an energy approach in order to show the influence of the process and the size ratio on the coating strength of composite particles. The larger the size ratio and the larger the mixing energy used, the better the coating quality, in term of coating adhesion. Among various prospects, torque measurement and force transducers set on the paddles would certainly bring more precise quantification of the mechanical action on the particles.

\section{Acknowledgements}

This work has been accomplished within the Biopowders project, a RTN Marie Curie action financed by the 6th European Framework Programme.

\section{References}

[1] R. Pfeffer, R. Dave, D. Wei, M. Ramlakhan, Synthesis of engineered particulates with tailored properties using dry particle coating, Powder Technology 117 (2001) 40-67.

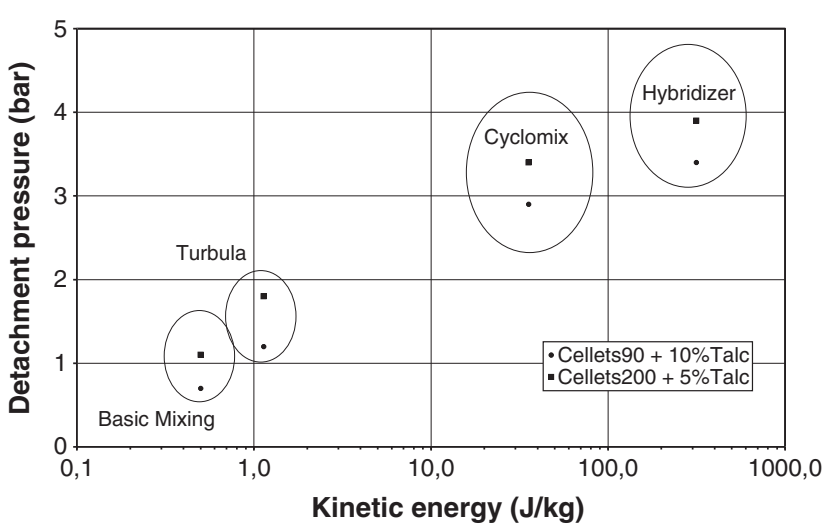

Fig. 9. Variation of coating strength with mixing kinetic energy in different apparatus.

[2] J. Yang, A. Sliva, A. Banerjee, R. Dave, R. Pfeffer, Dry particle coating for improving the flowability of cohesive powders, Powder Technology 158 (2005) 21-33.

[3] M. Ramlakhan, C. Wu, S. Watano, R. Dave, R. Pfeffer, Dry particle coating using magnetically assisted impaction coating: modification of surface properties and optimization of system and operating conditions, Powder Technology 112 (2000) 137-148.

[4] A. Mujumdar, D. Weia, R. Davea, R. Pfeffer, C. Wu, Improvement of humidity resistance of magnesium powder using dry particle coating, Powder Technology 140 (2004) 86-97.

[5] J.A. Hersey, Ordered mixing: a new concept in powder mixing, Powder Technology 11 (1975) 41-44.

[6] M. Alonso, M. Satoh, K. Myanami, Kinetic of fines transfer among carriers in powder coating, Powder Technology 59 (1989) 217-224.

[7] P. Singh, K. Solanky, R. Mudryy, R. Pfeffer, R. Dave, Estimation of coating time in the magnetically assisted impaction coating process, Powder Technology 121 (2001) 159-167.

[8] B.H. Ng, C.C. Kwan, Y.L. Ding, M. Ghadiri, X.F. Fan, Solids motion in a conical frustum-shaped high shear mixer granulator, Chemical Engineering Science 62 (2007) 756-765.

[9] S. Otles, O. Lecoq, J.A.D. Dodds, Dry particle high impact coating of biopowders : Coating strength, Particle Science and Technology 27:4 (2009) 352-361.

[10] A. Vilela, A. Chamayou, P. Accart, C. Rolland, M. Baron, J.A. Dodds, The evaluation of the strength of interactions between magnesium stearate and an active pharmaceutical substance coated by mechanical action, 8th International Symposium on Agglomeration, Bangkok, Thailand, March 16-18, 2005 pp. 285-294.

[11] E. Paul, V. Atiemo-Obeng, S. Kresta (Eds.), Handbook of industrial mixing : science and practice, John Wiley, 2004 